\title{
Three Museums in Berlin: Study on Protection and Renaissance Strategies of Historic Buildings
}

\author{
ZHAO Mei ${ }^{1, a^{*}}$, GUO Haoran ${ }^{2, b}$ and GAO Wei $\mathrm{W}^{3, \mathrm{c}}$ \\ ${ }^{1,2}$ School of Design and Art, Beijing Institute of Technology, Beijing, P. R. China \\ ${ }^{3}$ School of Architecture and Art, Beijing Jiaotong University, Beijing, P. R. China \\ amaezhao@qq.com, bguojiawei.chen@qq.com, cwgao@bjtu.edu.cn
}

Keywords: Historic Building; Protection; Renaissance; Berlin

Abstract. According to different characteristics of historic buildings, the strategies of the protection and renaissance can be different. Three representative museum buildings and several similar cases are selected in this paper to research the protection and renewal of historic buildings, expecting to promote the renaissance of historic buildings and development of cities in China.

\section{Introduction}

Historic buildings record and express the history and culture of cities. A preferable strategy to protect and develop these historic buildings and to pass on the city culture is always under consideration. Historic buildings incorporated unique symbolisms and spirits of places in different situations and different periods of history. Thus, in contemporary time, it is necessary to maintain and develop the historic characteristics selectively after seriously investigating the building itself and its surroundings, to remodeling the unique symbolisms and spirits of places. Berlin, as an example, has devoted itself for a long time to the protection and renaissance of historic buildings. After the WWII, lot of cases about different protection and renaissance strategies of historic buildings appeared in Berlin. Three representative museum buildings are selected in this paper. They are classified according to the intervention levels and are researched respectively.

\section{Low Intervention Level: Remaining Certain Period State}

\section{Kaiser Wilhelm Memorial Church Museum in Berlin}

The Kaiser Wilhelm memorial church museum was built in the end of the 19th century, locating at the Breitscheidplatz in Berlin. The whole museum has been destroyed in the WWII, except the three bell towers at the front of the building. This new Romanesque architecture with gothic elements was originally a famous royal church for large gatherings and weddings in Berlin. The government decided to repair it in 1959. It was found that the mottled walls and bombed tower spires seemed not ugly but characteristic and symbolic. Therefore, the vestige of this destroyed building was remained instead of repristination. At the same time, the church was transformed as a museum in memory of the war, while the new surrounding buildings was built and acted as the original cathedral (fig.2). The whole new building appears with concise sculpt and low-key facade color, which embodies the colorful appearance shape of original building. The contrast between the original buildings and new buildings forms a unique visual effect (fig.1), which making the revived Kaiser Wilhelm memorial church museum a fascinating landmark opposite the Berlin Central Station. These buildings beautify the city image and makeup the Berlin. 


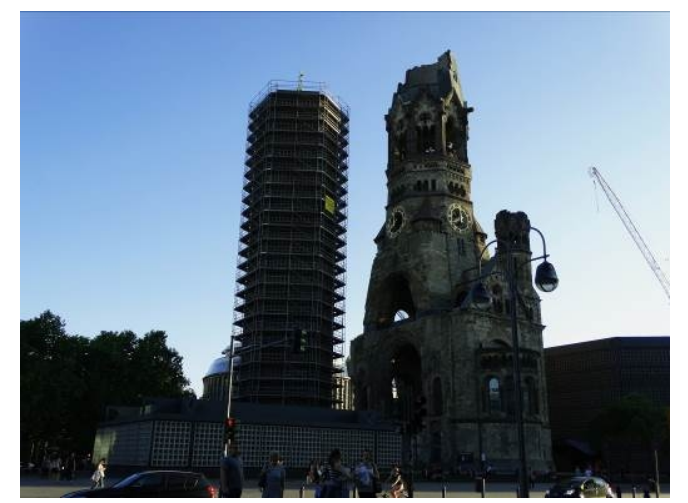

Fig. 1 Kaiser Wilhelm Memorial Church

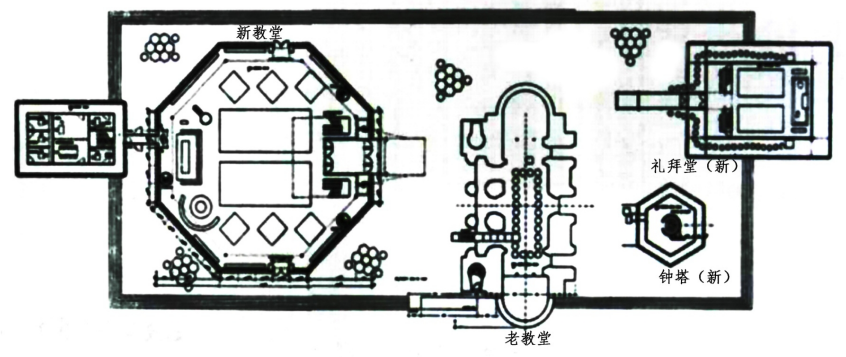

Fig. 2 The relationship between the old and new buildings

Form : W. Yang, A case study of historic building reconstruction in Germany

\section{Similar Examples in China}

There are some similar cases of keeping wrecked state of historic buildings, such as Yuanming Yuan. Yuanming Yuan is an outstanding achievement in China. However, it is almost burned out and destroyed by the Anglo-French Allied Force. During the process of protection and renaissance, the architecture site was completely remained without any reparation. Furthermore, a relic park with part of the original garden landscape was built on the large scale of the site, to retain the authenticity and completeness of the history.

\section{Summary}

Remaining a certain period state is the minimum intervention to the original historic building, during the process of protection and renaissance. With time goes by, historic buildings reflect period knowledge and attitude. Thus, the symbolisms and spirits, which reflect the contemporary public perception, should be explored to protect and revitalize historic buildings in the modern environment.

\section{Middle Intervention Level: Combining Old and New}

\section{Neues Museum in Berlin}

A principle of inheriting critically and selectively was proposed during the cautious urban renewal process after the WWII. The Neues Museum in Berlin was built from 1841. A big high stairway links together three-floor circulation space inside the building and divides two atriums. The luxurious interior, the concise neoclassical sculpt, and the advanced material in that period, all made this building quite meaningful in the architectural history. The museum had been bombed out in the WWII and was repaired abiding by the principle of "the protective reconstruction". The northwest and the southeast corners were completed (fig. 3). The central stairway inside was repaired with the modern polished concrete according to the original shape and structure, considering its function to connect circulation spaces. The original components were used to repair the building interior. The figure 4 shows that the classical pillars copy from originals were still load-bearing (fig. 4). The frescos and components falling from walls were filled up by similar materials. The lighting system and the display racks were built as concise as possible, keeping the interior space historic. The new materials and structures that used where can not be completely repaired were follow the principle of concise and low-key, which made the original and new elements recognizable and won't confusing the history. Meanwhile, the materials from the ruins were reused in the reparation as far as possible to perpetuating the history. The revived Neues Museum respects the original historic characteristics in the aspects of space and configuration. The completeness and the uniformity make the building blending well in modern environment with the authenticity of history. 


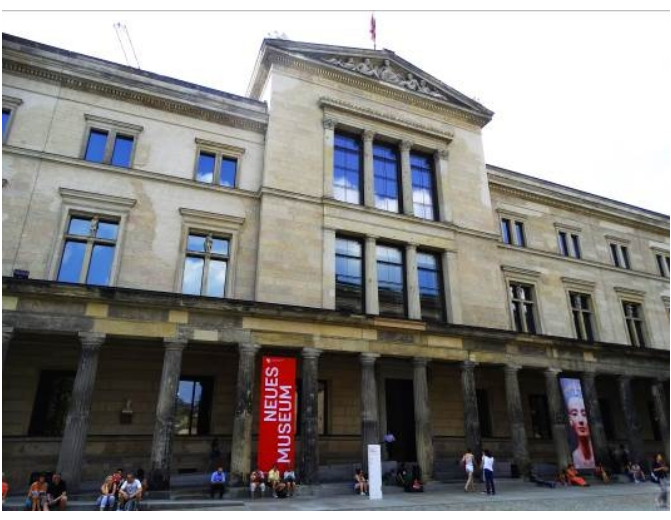

Fig. 3 Current situation of the Neues Museum

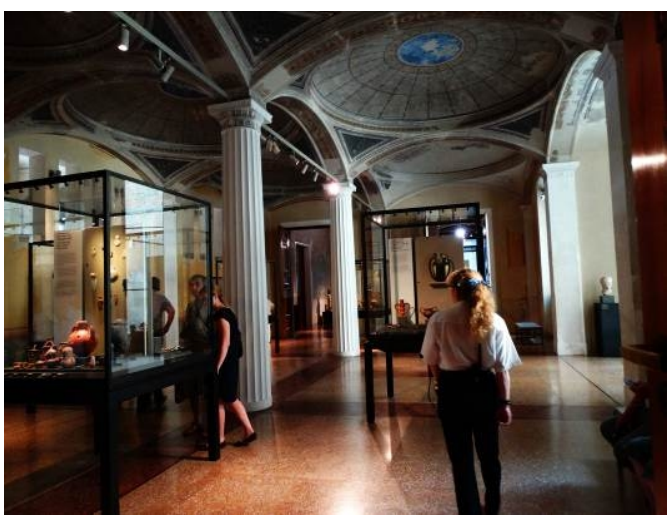

Fig. 4 Interior of the Neues Museum

\section{Similar Examples in China}

The Xintiandi in Shanghai, the Kuanxiangzi and Zhaixiangzi in Chengdu, Sichuan and the Laowaitan in Ningbo, Zhejiang, are all cases following the renaissance strategy of combining old elements and new elements. The Xintiandi in Shanghai was revived by reparation and reconstruction the ancient buildings at the Shikumen lanes and alleys, using the similar material as original, while the modern commercial design were used inside to create an atmosphere of business. The change of the function of Xintiandi and the introduction of commercial elements made the old buildings at Shikumen area a scenery line of city, where combine the history and art. The Laowaitan in Ningbo is located at the convergence of three rivers and was the most flourishing port from Tang Dynasty and Song Dynasty. Some old buildings there, such as police station, old shops and foreign consulate, are historic buildings that contain the features from Britain, France, Germany and Holland. At the beginning of this century, designers redesigned and rebuilt the blocks in Laowaitan district. The architectural style combined China and the West was remained. Furthermore, the postmodernism was blended into the new buildings, which made this district features traditional and fashion. The historical relics and the old and new buildings formed witnesses of different historical periods, especially reviving the charm in 1940s.

\section{Summary}

It is necessary to introduce new elements for the protection and renaissance of historic buildings. The key point is harmonizing the old and new elements and remaining the authenticity of building history. No matter the building reparation of the Neues Museum in Berlin, which mostly respected the history, or the strong intervention by new elements in the Xintiandi in Shanghai, different levels of combination of old and new elements would all make the historic building playing a new role in a new environment while continuing the historical context.

\section{High Intervention Level: Rebuilding as Original Appearance}

\section{Berlin Wall Memorial in Berlin}

The Berlin Wall with a 28-year history witnesses the US-Soviet Cold-War and leaves a painful memory. It was a symbolic building that divided the Berlin into East Berlin and West Berlin at that time. The Berlin Wall was almost destroyed out after the reunification. The government rebuilt the Berlin Wall to in memory of the tough and sensitive history. The Berlin Wall memorial was rebuilt on the original site in the memorial park located at the north side of the Bernauer Street (fig. 5). The landscape park and the Berlin Wall memorial were built surrounding the Berlin Wall. At the same time, the route was identified by marking the "BERLIN MAUER 1961-1989" on the iron with polished slabs at the central of the road (fig. 6). Also, part of the relic of the Berlin Wall is exhibitioned by open museum and graffiti exhibit. The verisimilar history is shown publicly. All these protection and renaissance are the reappearances of the history about the Berlin Wall. 


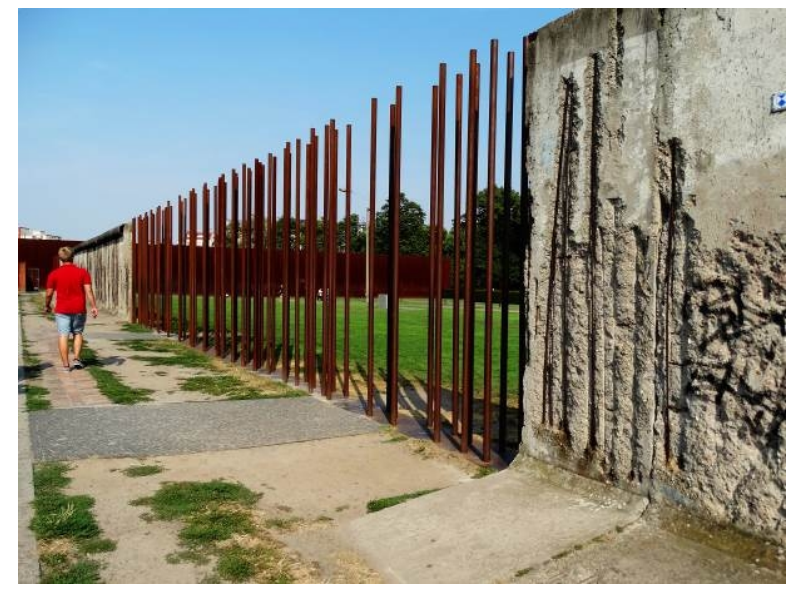

Fig. 5 Berlin Wall Memorial Park

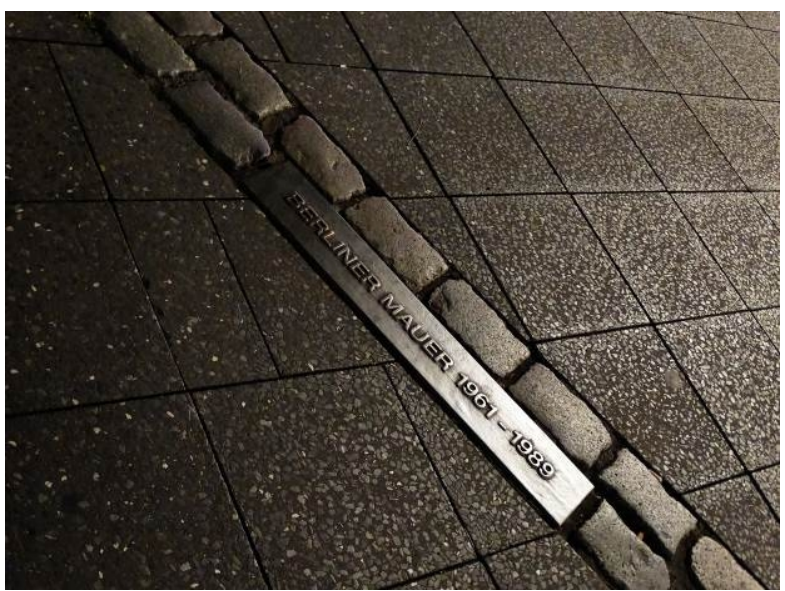

Fig. 6 Marks on the foot of the Berlin wall

\section{Similar Examples in China}

It needs regular maintenance and reparation for historic buildings in China because of the fugitiveness of woodiness and soil materials. Historic buildings contain the different characteristics of different dynasties. The design styles and features in early Nan Song dynasty were used during the protection and renaissance of the Leifeng pagoda to shape the whole outline of West Lake. The repaired Leifeng pagoda remodels the spirt of spaces in the West Lake to reappear the beautiful scenery.

\section{Summary}

Unquestionably, as for some destroyed buildings, rebuilding as original appearance is an appropriate strategy to revivification the appearance and history. Meanwhile, the history and culture behind the historic buildings needs to be lucubrated. The necessity to revived historic buildings should also be measured to avoid the value and culture of historic building from damaging by rebuilding excessively.

\section{Conclusion}

The protection and renaissance strategies of historic buildings are analyzed through different intervention levels in this paper. The intervention levels are based on the extents of characteristics and history remained. Different strategies, such as remaining certain period state, combining old and new and rebuilding as original appearance, should be adopted according to the characteristics of the historic buildings. Besides, the protections and renaissances of historic buildings can not leave the background of city development. The essence of the renaissances of historic buildings is to continue the historical context. The difficulty of the renaissances of historic buildings is to adapt the buildings to the development using the limited resources with limited resources. In another words, the historic buildings need to play a new role with new meanings. Every historic building is not only the accumulation through every historical period, but also the result of joint actions between itself and historical environments. Thus, the origin from historic buildings should be investigated and the protections and renaissances should be selective. Nowadays, urbanization in China is still developed rapidly, while in the exploratory stage of the protections and renaissances of historic buildings. Inevitably, some historic buildings are still under the danger of damage by economic development. Therefore, it is necessary to raise the protection awareness, betterment the institutions and continue the study and research on the relevant aspects.

Image : All the pictures in this paper are from the author except the figure 2. 


\section{Acknowledgements}

This work was financially supported by Beijing Higher Education Young Elite Teacher Project (Grant No. YETP1228) and the State Scholarship Fund.

\section{References}

[1] C. Yu, C. Gong, Restoring the old as before: long-lasting city heritages, Urban Management (in Chinese). 05 (2012) 76-81.

[2] Z.D. Li, Faithful to history: the base of historic buildings protection in Berlin, Shanghai Real Estate (in Chinese). 08 (2010) 52.

[3] Z.Z. Wu, R. Zhao, Restoring the old as before in historic buildings: restoring the old as before in the protection of Ming Great Wall in northern Shaanxi, Urban Problems (in Chinese). 02 (2014) 36-40.

[4] Y.Q. Yang, Reuse of historic buildings in urban evolution, Journal of Lanzhou University of Technology (in Chinese). 09 (2011) 263-266.

[5] W. Yang, A case study of historic building reconstruction in Germany, Urban Space Design (in Chinese). 01 (2005) 102-108.

[6] Y. Zuo, The experience and enlightenment of protection and revitalization of industrial building heritage in Berlin (in Chinese), Doctoral Dissertation of Tongji University, 2005.

[7] H. Wang, The case study of Berlin Neues museum building protection and update (in Chinese), Master Dissertation of Zhengzhou University, 2014. 